\title{
Risk stratification and prognostic effects of internal thoracic artery grafting during acute myocardial infarction
}

\author{
Manuel Caceres, MD, ${ }^{\mathrm{a}, \mathrm{b}}$ Xia He, MS, ${ }^{\mathrm{c}}$ James Scott Rankin, MD, ${ }^{\mathrm{d}}$ Darryl S. Weiman, MD, ${ }^{\mathrm{e}}$ and \\ Harvey Edward Garrett, Jr, MD ${ }^{\mathrm{a}, \mathrm{e}}$
}

\begin{abstract}
Objective: Surgeons are occasionally requested to perform coronary artery bypass grafting during acute myocardial infarction. We intended to test the safety of coronary artery bypass grafting and internal thoracic artery grafting early after myocardial infarction using the Society of Thoracic Surgeons database.
\end{abstract}

\begin{abstract}
Methods: The database was queried for isolated coronary artery bypass grafting less than 24 hours after a myocardial infarction from 2002 to 2008. By using multivariable logistic regression and classification trees, risk models were created to stratify this group of patients. The independent prognostic effect of internal thoracic artery grafting was examined using standard risk-adjusted mortality comparisons.
\end{abstract}

\begin{abstract}
Results: A total of 44,141 patients were identified, with an overall operative mortality of $7.9 \%$. Cardiogenic shock occurred in $21 \%$, percutaneous coronary intervention within 6 hours before surgery was performed in $11 \%$, myocardial infarction within 6 hours before surgery occurred in $37 \%$, preoperative intra-aortic balloon pump was used in $50 \%$, and internal thoracic artery grafting was performed in $79 \%$ of the patients. Myocardial infarction in less than 24 hours was associated with higher operative mortality (odds ratio, 3.25) and major morbidity (odds ratio, 2.54). Emergency/salvage status (odds ratio, 6.43), age more than 80 years (odds ratio, 4.07), dialysis (odds ratio, 3.08), and cardiogenic shock (odds ratio, 2.79) were independent mortality predictors. Patients with nonemergence salvage status, absence of cardiogenic shock, creatinine less than $1.5 \mathrm{mg} / \mathrm{dL}$, and age less than 70 years represented $48 \%$ of the population and exhibited a lower mortality rate of $2 \%$. Internal thoracic artery grafting was independently associated with a lower risk of mortality (odds ratio, $0.52 ; P<.0001$ ) and did not seem to compromise outcomes.
\end{abstract}

Conclusions: Coronary artery bypass grafting less than 24 hours after myocardial infarction carries a higher operative risk but can be performed safely in selected patients. Although confounding variables may exist, internal thoracic artery grafting was associated with improved outcomes. Internal thoracic artery use in this setting is less than ideal, and taking time to harvest internal thoracic artery grafts in patients with acute myocardial infarction might be encouraged. (J Thorac Cardiovasc Surg 2013;146:78-84)

During the last decade, several randomized and nonrandomized studies and major society guidelines have established percutaneous coronary intervention (PCI) as the first line of treatment for acute myocardial infarction (MI). ${ }^{1-8}$ However, situations exist in which coronary artery bypass grafting $(\mathrm{CABG})$ becomes appropriate in patients with acute MI, for example, unsuitable coronary anatomy for PCI, left main disease, severe 3-vessel disease, and failed PCI. It is generally agreed that the operative risk is higher

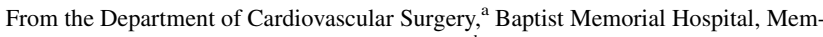
phis, Tenn; Department of Thoracic Surgery, ${ }^{\mathrm{b}}$ Cedars Sinai Medical Center, Los Angeles, Calif; Duke Clinical Research Institute, ${ }^{c}$ Duke University, Durham, NC; Centennial Medical Center, ${ }^{\mathrm{d}}$ Vanderbilt University, Nashville, Tenn; and Department of Thoracic Surgery, ${ }^{\mathrm{e}}$ The University of Tennessee Health Science Center, Memphis, Tenn.

Disclosures: Authors have nothing to disclose with regard to commercial support.

Received for publication Jan 19, 2012; revisions received April 10, 2012; accepted for publication May 15, 2012; available ahead of print June 28, 2012.

Address for reprints: Manuel Caceres, MD, 8700 Beverly Blvd, SCCT, Room 2S03, Los Angeles, CA 90048 (E-mail: Caceres_manuel@hotmail.com). $0022-5223 / \$ 36.00$

Copyright (C) 2013 by The American Association for Thoracic Surgery http://dx.doi.org/10.1016/j.jtcvs.2012.05.073
}

in these patients, but precise risk characteristics have not been defined. Finally, in patients with acute MI and ongoing ischemia, there is controversy whether to spend time harvesting the internal thoracic artery (ITA) versus performing more rapid revascularization with a saphenous vein graft. This study was undertaken within the Society of Thoracic Surgeons (STS) database to investigate these issues.

\section{MATERIALS AND METHODS \\ Data Source}

The STS database is a voluntary program developed in 1986 to provide risk-adjusted outcomes based on the national cardiac surgical experience. It has expanded over the last 2 decades to represent approximately $90 \%$ of the cardiac surgery programs in North America. ${ }^{9,10}$ Research on the STS database is conducted by the Duke Clinical Research Institute and approved by the Duke University Institutional Review Board. Patient privacy is protected by standard processes in data collection and submission established by the STS and executed by participating institutions. Patients undergoing isolated CABG less than 24 hours after MI were identified from January 2002 to December 2008. Patient selection was limited to an acuity status of urgent, emergency, or emergency/salvage. Records with missing information about age, gender, MI, PCI, acuity status, or cardiogenic shock were excluded $(<3 \%$ of patients). 


\section{Abbreviations and Acronyms \\ $\mathrm{CABG}=$ coronary artery bypass grafting \\ IABP $=$ intra-aortic balloon pump \\ ITA $=$ internal thoracic artery \\ MI = myocardial infarction \\ $\mathrm{OR} \quad=$ odds ratio \\ PCI = percutaneous coronary intervention \\ SHOCK $=$ SHould we emergently revascularize \\ Occluded Coronaries for cardiogenic shock \\ STS $=$ Society of Thoracic Surgeons}

\section{Study Design and Statistical Analysis}

Clinical definitions for all relevant prognostic variables have been established and can be accessed at www.sts.org. Candidate variables and coding were consistent with the STS 2008 cardiac surgery risk models. ${ }^{9}$ A variable for "time trend" was included to adjust for temporal changes in specific variables that may occur coincidentally with a decline in mortality rates. To prevent identifying an unwarranted causal inference with mortality, the STS National Coverage Determination uses "date of surgery" in 6-month intervals to adjust for temporal changes in the frequency of explanatory variables and adverse outcomes.

Preoperative, operative, and postoperative variables were compared in patients with and without MI less than 24 hours before surgery. Continuous variables were compared with the Wilcoxon rank-sum test, and categoric variables were compared with the Pearson chi-square test. Missing predictor variables were replaced according to imputation strategies previously established by the STS database. ${ }^{9}$ Single-effect and multiple logistic regression analyses were conducted to create risk models of operative mortality, including and excluding ITA grafting. Pair interactions of ITA grafting with age, reoperation, cardiogenic shock, and acuity status were entered in the model and tested by using the Wald statistic.

The group with MI less than 24 hours before surgery was divided into quintiles of increasing predicted risk, and operative mortalities with and without ITA grafting were compared within each quintile. To further exclude the bias of avoiding ITA grafting in more critical patients, this comparison was repeated after excluding cardiogenic shock, emergency/ salvage status, and resuscitation. A classification tree was developed from the multivariable analysis to identify subgroups with a similar mortality risk by using clinically relevant variables with the highest discrimination of operative mortality. This approach yielded subgroups with minimal entropy subject to the constraint that each variable was split only once, and patients in a high-risk subgroup were not further subdivided. The selected tree minimizes the sum of entropy in all leaves among all possible trees with the same structure.

\section{RESULTS \\ Patient Characteristics}

From 2002 to 2008, MI less than 24 hours before surgery was present in $7.6 \%$ of patients undergoing isolated CABG $(44,141 / 578,398)$. The baseline characteristics are shown in Table 1. Because of the large sample size, most variables achieved statistical significance between MI in less than 24 hours and other patients undergoing isolated CABG, but clinically, most variables were similar between both groups. Variables reflecting a higher acuity of presentation

were more prevalent in the group with an $\mathrm{MI}$ in less than 24 hours, such as cardiogenic shock, resuscitation, preoperative intra-aortic balloon pump (IABP), inotropic use, a lower ejection fraction, and a higher acuity status. ITA grafting was used in $79 \%$ of the patients with MI in less than 24 hours and $90 \%$ of the patients without MI in less than 24 hours.

\section{Outcome Comparisons}

Compared with patients who did not have an MI in less than 24 hours before CABG, operative mortality and combined major morbidity and mortality were significantly higher in the group with an MI in less than 24 hours ( $7.9 \%$ vs $2.6 \%$ and $33.7 \%$ vs $16.7 \%$, respectively). Differences in operative mortality were more pronounced as patients with an MI in less than 24 hours were further divided into (1) MI in 6 hours or less and (2) MI in 6 to 24 hours $(10.8 \%$ vs $6.3 \%, P<.001)$. ITA grafting correlated with the priority of $\mathrm{CABG}$, with $70.5 \%$ use in the group with MI in 6 hours or less and $83.9 \%$ in the group with MI in 6 to 24 hours. Of particular interest were the patients in cardiogenic shock, in whom only $56.9 \%$ received ITA grafting. Except for deep sternal wound infection and postoperative MI, operative morbidity was significantly higher in the group with MI in less than 24 hours.

\section{Selected High-Risk Categories and Univariable/ Multivariable Risk Models}

Operative mortality was significantly higher in emergency/salvage versus urgent status $(31.7 \%$ vs $5.9 \%)$, cardiogenic shock $(22.3 \%$ vs $4 \%$ ), age more than 80 years ( $16.7 \%$ vs $7.1 \%)$, preoperative dialysis $(23.4 \%$ vs $4.9 \%)$, PCI in less than 6 hours $(14.2 \%$ vs $7.2 \%)$, presence of IABP $(10.6 \%$ vs $5.2 \%)$, and ejection fraction less than $40 \%(12.9 \%$ vs $5.7 \%)$. Of note, patients not receiving ITA grafting comprised $21 \%$ of the study population and had an approximately 5-fold higher unadjusted mortality compared with those receiving ITA grafting $(19.1 \%$ vs $5.0 \%$ ) (Table 2). Univariable analysis revealed age more than 80 years (odds ratio [OR], 3.53), creatinine greater than $1.5 \mathrm{mg} / \mathrm{dL}(\mathrm{OR}, 3.06)$, congestive heart failure New York Heart Association IV (OR, 3.55), emergency (OR, 2.67) or emergency/salvage status (OR, 13.62), cardiogenic shock (OR, 6.68), preoperative IABP/inotropes (OR, 2.7), ejection fraction less than $30 \%$ (OR, 2.41), mitral insufficiency (OR, 2.66), and tricuspid insufficiency (OR, 3.44) to have the highest association with operative mortality. Finally, ITA grafting was strongly associated with lower operative mortality (OR, 0.22).

Multivariable logistic regression excluding ITA grafting identified emergency/salvage status (OR, 6.43), age more than 80 years (OR, 4.07), dialysis-dependent renal failure (OR, 3.08), and cardiogenic shock (OR, 2.79) to have the highest independent association with operative mortality. 
TABLE 1. Baseline characteristics

\begin{tabular}{|c|c|c|c|}
\hline Characteristics & MI 0-24 h & No MI 0-24 h & $\begin{array}{c}P \\
\text { value }\end{array}$ \\
\hline Sample size, $n,(\%)$ & $44,141(7.6 \%)$ & $534,257(92.4 \%)$ & \\
\hline \multicolumn{4}{|l|}{ Demographics } \\
\hline Age, y, mean (IQR) & $63.2(55-72)$ & $65.2(57-74)$ & $<.0001$ \\
\hline Female, \% & 27.0 & 29.0 & $<.0001$ \\
\hline Caucasian, $\%$ & 72.0 & 70.9 & $<.0001$ \\
\hline \multicolumn{4}{|l|}{ Medical history } \\
\hline Diabetes, $\%$ & 28.7 & 37.1 & $<.0001$ \\
\hline Hypertension, $\%$ & 70.1 & 79.6 & $<.0001$ \\
\hline Hypercholesterolemia, \% & 62.2 & 76.2 & $<.0001$ \\
\hline Smoker, \% & 57.6 & 56.7 & $<.0001$ \\
\hline $\begin{array}{l}\text { COPD (moderate/ } \\
\text { severe), } \%\end{array}$ & 8.9 & 10.4 & $<.0001$ \\
\hline $\begin{array}{l}\text { Peripheral vascular } \\
\text { disease, } \%\end{array}$ & 11.8 & 15.5 & $<.0001$ \\
\hline $\begin{array}{l}\text { Cerebrovascular } \\
\text { disease, } \%\end{array}$ & 9.7 & 14.0 & $<.0001$ \\
\hline Preoperative dialysis, $\%$ & 1.1 & 1.9 & $<.0001$ \\
\hline $\begin{array}{l}\text { Immunosuppressive } \\
\text { treatment, \% }\end{array}$ & 1.8 & 2.3 & $<.0001$ \\
\hline Congestive heart failure, $\%$ & 20.2 & 17.1 & $<.0001$ \\
\hline Prior cardiac surgery, $\%$ & 4.8 & 6.4 & $<.0001$ \\
\hline \multicolumn{4}{|l|}{ Preoperative characteristics } \\
\hline $\begin{array}{l}\text { Serum creatinine, } \mathrm{mg} / \mathrm{dL}, \\
\text { mean }(\mathrm{IQR})\end{array}$ & $1.15(0.90-120)$ & $1.18(0.90-120)$ & $<.0001$ \\
\hline Preoperative $\mathrm{MI}<6 \mathrm{~h}, \%$ & 37.0 & 0.00 & $<.0001$ \\
\hline Preoperative MI 6-24 h, \% & 63.0 & 0.00 & $<.0001$ \\
\hline $\mathrm{PCI}<6 \mathrm{~h}, \%$ & 10.6 & 0.96 & $<.0001$ \\
\hline Cardiogenic shock, $\%$ & 21.2 & 2.1 & $<.0001$ \\
\hline Resuscitation, \% & 7.8 & 0.9 & $<.0001$ \\
\hline Preoperative IABP, \% & 50.3 & 10.7 & $<.0001$ \\
\hline Preoperative inotropes, $\%$ & 12.2 & 2.1 & $<.0001$ \\
\hline Left main disease, $\%$ & 36.5 & 34.8 & $<.0001$ \\
\hline Three vessel disease, $\%$ & 75.4 & 76.9 & $<.0001$ \\
\hline $\begin{array}{l}\text { Ejection fraction, \%, } \\
\text { mean (IQR) }\end{array}$ & $43.5(35-55)$ & $49.9(40-60)$ & $<.0001$ \\
\hline $\begin{array}{l}\text { Mitral regurgitation } \\
\quad \text { (moderate/severe), \% }\end{array}$ & 3.7 & 3.2 & $<.0001$ \\
\hline $\begin{array}{l}\text { Tricuspid regurgitation } \\
\text { (moderate/severe), \% }\end{array}$ & 1.1 & 1.2 & .004 \\
\hline Acuity status urgent, $\%$ & 43.2 & 94.9 & $<.0001$ \\
\hline $\begin{array}{l}\text { Acuity status } \\
\text { emergency, \% }\end{array}$ & 48.9 & 4.7 & $<.0001$ \\
\hline $\begin{array}{l}\text { Acuity status } \\
\text { emergency/salvage, } \%\end{array}$ & 8.0 & 0.4 & $<.0001$ \\
\hline
\end{tabular}

(Continued)

After including ITA grafting in the multivariable model, the original variables remained statistically significant, and ITA grafting continued to be associated with reduced operative mortality (OR, 0.52; confidence interval, 0.47-0.57; $P<.0001$ ). Results of the multivariable analysis are summarized in Table 3.

Interactions of ITA grafting with age, previous cardiac operations, cardiogenic shock, and emergency/salvage
TABLE 1. Continued

\begin{tabular}{|c|c|c|c|}
\hline Characteristics & MI 0-24 h & No MI 0-24 h & $\begin{array}{c}P \\
\text { value }\end{array}$ \\
\hline \multicolumn{4}{|l|}{ Operative variables } \\
\hline Off-pump CABG, $\%$ & 16.2 & 19.9 & $<.0001$ \\
\hline $\begin{array}{l}\text { Perfusion time, min, } \\
\text { mean (IQR) }\end{array}$ & $101.1(73-121)$ & $98.1(72-118)$ & $<.0001$ \\
\hline $\begin{array}{l}\text { Crossclamp time, min, } \\
\text { mean (IQR) }\end{array}$ & $67.0(46-83)$ & $68.1(47-84)$ & $<.0001$ \\
\hline ITA grafting, $\%$ & 79.0 & 90.3 & $<.0001$ \\
\hline $\begin{array}{l}\text { Insertion of ventricular } \\
\text { assist device, } \%\end{array}$ & 0.8 & 0.2 & $<.0001$ \\
\hline
\end{tabular}

status were tested. The Wald statistic showed that the interactions ITA*ardiogenic shock $(P=.058)$ and ITA*reoperation $(P=.297)$ were not significant, and thus were excluded from the model. According to these findings, the positive effect of ITA grafting on operative mortality did not differ significantly in patients with or without cardiogenic shock or in patients with or without reoperation.

\section{Risk Stratification}

After quintile risk stratification, a significant difference in mortality was observed in each risk quintile $(P<.001)$ in favor of ITA grafting, except for the lowest risk quintile $(P=.43)$. Similar results were obtained after excluding cardiogenic shock, emergency/salvage status, and resuscitation. The adjusted effect of ITA grafting in the group with MI in less than 24 hours is summarized in Figure 1.

A classification tree identified a group of patients with an acceptable mortality risk of $2 \%$. The classification tree started with 44,141 patients and was divided successively by the following variables: emergency/salvage status (mortality, $31.7 \%$ ), cardiogenic shock (mortality, 16.6\%), dialysis or creatinine greater than $1.5 \mathrm{mg} / \mathrm{dL}$ (mortality, $9.0 \%$ ), and age more than 70 years (mortality, $6.1 \%$ ). The remaining patients without any of these risk factors $(21,523)$ comprised $48.7 \%$ of the initial study population and had an operative mortality of $2 \%$ (Figure 2 ).

\section{DISCUSSION}

Optimal selection of patients with acute MI for surgical revascularization has been an area of interest and intense debate, ${ }^{2-4,11}$ and mortality rates have varied from $3.6 \%$ to $23.8 \% .^{2-4,12}$ Current information originates primarily from single institutional studies with low patient samples, and results may be biased by varied institutional preferences. To date, no data are available regarding ITA grafting during acute MI, and the STS database represents an opportunity to clarify details of this issue. Although 
TABLE 2. Unadjusted mortality and morbidity rates and internal thoracic artery grafting in high-risk subgroups of coronary artery bypass grafting less than 24 hours after myocardial infarction

\begin{tabular}{|c|c|c|c|c|c|c|c|}
\hline High-risk variable & Frequency, \% & Mortality, \% & Permanent stroke, $\%$ & Renal failure, $\%$ & Prolonged ventilation, $\%$ & DSWI, \% & ITA, \% \\
\hline \multicolumn{8}{|l|}{ Cardiogenic shock } \\
\hline Yes & 21.2 & 22.4 & 4.1 & 16.4 & 56.7 & 0.8 & 56.7 \\
\hline No & 78.8 & 4.1 & 2.0 & 5.4 & 21.2 & 0.5 & 84.9 \\
\hline \multicolumn{8}{|l|}{ Age $>80 y$} \\
\hline Yes & 8.8 & 16.7 & 4.0 & 15.5 & 38.6 & 0.6 & 69.0 \\
\hline No & 91.2 & 7.1 & 2.3 & 7.0 & 27.7 & 0.6 & 79.9 \\
\hline \multicolumn{8}{|l|}{ Acuity status, salvage } \\
\hline Yes & 8.0 & 31.7 & 4.2 & 18.1 & 57.4 & 0.8 & 42.8 \\
\hline No & 92.1 & 5.9 & 2.3 & 6.8 & 26.2 & 0.5 & 82.1 \\
\hline \multicolumn{8}{|c|}{ Preoperative renal insufficiency } \\
\hline Dialysis & 1.1 & 23.4 & 4.4 & 7.1 & 51.5 & 1.1 & 71.6 \\
\hline Creatinine $>1.5$ & 10.9 & 17.6 & 4.5 & 22.6 & 45.9 & 0.7 & 69.4 \\
\hline Creatinine 1.0-1.5 & 51.8 & 7.7 & 2.2 & 7.5 & 28.4 & 0.6 & 79.1 \\
\hline Creatinine $<1.0$ & 36.2 & 4.9 & 2.00 & 3.7 & 23.2 & 0.5 & 82.0 \\
\hline \multicolumn{8}{|l|}{$\mathrm{PCI}<6 \mathrm{~h}$} \\
\hline Yes & 10.6 & 14.2 & 2.6 & 10.5 & 37.5 & 0.6 & 57.9 \\
\hline No & 89.4 & 7.2 & 2.4 & 7.4 & 27.7 & 0.6 & 81.4 \\
\hline \multicolumn{8}{|l|}{ Preoperative $\mathrm{MI}<6 \mathrm{~h}$} \\
\hline Yes & 36.7 & 10.8 & 2.5 & 9.0 & 33.5 & 0.6 & 70.5 \\
\hline No & 63.0 & 6.3 & 2.4 & 7.0 & 25.9 & 0.5 & 83.9 \\
\hline \multicolumn{8}{|l|}{ IABP } \\
\hline Yes & 50.3 & 10.6 & 2.8 & 9.8 & 39.9 & 0.6 & 74.6 \\
\hline No & 49.7 & 5.2 & 2.1 & 5.7 & 17.4 & 0.4 & 83.4 \\
\hline \multicolumn{8}{|l|}{$\mathrm{EF}<40 \%$} \\
\hline Yes & 31.1 & 12.9 & 3.3 & 11.3 & 41.8 & 0.7 & 73.6 \\
\hline No & 68.9 & 5.7 & 2.0 & 6.1 & 22.9 & 0.5 & 81.4 \\
\hline \multicolumn{8}{|l|}{ ITA grafting } \\
\hline Yes & 79.0 & 5.0 & 2.1 & 6.1 & 24.5 & 0.6 & 100.0 \\
\hline No & 21.0 & 19.1 & 3.5 & 14.0 & 44.4 & 0.5 & 0.0 \\
\hline
\end{tabular}

$D S W I$, Deep sternal wound infection; $I T A$, internal thoracic artery; $P C I$, percutaneous coronary intervention; $M I$, myocardial infarction; $I A B P$, intra-aortic balloon pump; $E F$, ejection fraction.

surgical approaches need to be individualized to each specific patient, perhaps some general concepts can be developed on the basis of the nationwide experience.

Benefits of early revascularization in cardiogenic shock have been documented in the SHould we emergently revascularize Occluded Coronaries for cardiogenic shocK (SHOCK) trial, showing a lower 6-month mortality compared with initial medical stabilization $(50.3 \%$ vs $63.1 \%$, $P<.027) .{ }^{13}$ Mehta and colleagues ${ }^{14}$ found a $22 \%$ mortality for isolated CABG during shock, with $38.8 \%$ of the patients presenting with MI less than 24 hours before surgery. In the present study, $21.2 \%$ of patients with MI less than 24 hours before surgery presented in shock with a mortality of $22.3 \%$. The lower STS mortality may relate to different selection criteria used in the SHOCK trial, which included a time frame for early revascularization up to 54 hours after MI. ${ }^{13}$

Several high-risk groups were identified in the STS data set with remarkably elevated mortality rates: emergency/ salvage status $(31.7 \%)$, dialysis-dependent renal failure $(23.4 \%)$, creatinine greater than $1.5 \mathrm{mg} / \mathrm{dL}(17.6 \%)$, age more than 80 years $(16.7 \%)$, and PCI less than 6 hours before surgery $(14.2 \%)$. Haan and colleagues ${ }^{15}$ presented the STS experience of PCI less than 6 hours before $\mathrm{CABG}$ in the setting of $\mathrm{MI}$ and reported an increase in surgical mortality from $13.6 \%$ to $16.3 \%$ over a decade, despite general improvements in isolated CABG outcomes. These ultra high-risk groups have not been addressed in previous studies, and the suboptimal outcomes suggest that lessinvasive PCI approaches should be considered in many of these categories whenever possible. ${ }^{9}$

Classification tree methodology in outcomes research is a simple and valuable technique to stratify high-risk patients and identify subpopulations with favorable risk profiles. ${ }^{16-18}$ A substantial number of patients undergoing CABG early after MI, showing an acceptable mortality risk, were identified in this study $(48.8 \%$ had a mortality of $2 \%)$ (Figure 2). The patients with a surgical indication for CABG early in the hours of an MI have not been previously risk stratified, but a large proportion can safely undergo operation, as required in clinical practice. This finding dispels one common overgeneralization that $\mathrm{CABG}$ early after MI carries a prohibitive risk. Clearly, many 
TABLE 3. Multivariable logistic regression model of operative mortality (not including internal thoracic artery grafting)

\begin{tabular}{|c|c|c|c|c|}
\hline Variable & $\begin{array}{l}\text { Odds } \\
\text { ratio }\end{array}$ & $95 \% \mathrm{CI}$ & $\begin{array}{c}\text { Wald } \\
\text { chi-square }\end{array}$ & $\begin{array}{c}P \\
\text { value }\end{array}$ \\
\hline Age 70 vs 50 y & 2.21 & $1.80-2.73$ & 55.70 & $<.0001 *$ \\
\hline Age 80 vs 50 y & 4.07 & $3.13-5.30$ & 108.51 & $<.0001 *$ \\
\hline Female vs male & 1.29 & $1.15-1.45$ & 19.27 & $<.0001 *$ \\
\hline Race, Asian & 0.86 & $0.66-1.14$ & 1.09 & .2956 \\
\hline Race, Black & 1.01 & $0.85-1.2$ & 0.01 & .9227 \\
\hline Race, Hispanic & 1.19 & $0.97-1.47$ & 2.69 & .1012 \\
\hline Creatinine 1.5 vs $1.0 \mathrm{mg} / \mathrm{dL}$ & 1.81 & $1.60-2.06$ & 85.00 & $<.0001 *$ \\
\hline Creatinine 2.0 vs $1.0 \mathrm{mg} / \mathrm{dL}$ & 1.96 & $1.74-2.21$ & 122.67 & $<.0001 *$ \\
\hline Creatinine 2.5 vs $1.0 \mathrm{mg} / \mathrm{dL}$ & 2.13 & $1.83-2.47$ & 100.19 & $<.0001 *$ \\
\hline Dialysis vs creatinine $1.0 \mathrm{mg} / \mathrm{dL}$ & 3.08 & $2.33-4.06$ & 63.29 & $<.0001 *$ \\
\hline $\mathrm{EF} 40 \%$ vs $50 \%$ & 1.19 & $1.14-1.24$ & 74.20 & $<.0001 *$ \\
\hline EF $30 \%$ vs $50 \%$ & 1.41 & $1.31-1.53$ & 74.20 & $<.0001 *$ \\
\hline $\begin{array}{l}\text { BSA } 1.6 \text { vs } 2.0 \text { among male } \\
\text { patients }\end{array}$ & 1.53 & $1.26-1.85$ & 18.70 & $<.0001^{*}$ \\
\hline $\begin{array}{l}\text { BSA } 1.8 \text { vs } 2.0 \text { among male } \\
\text { patients }\end{array}$ & 1.14 & $1.06-1.23$ & 13.65 & $.0002 *$ \\
\hline $\begin{array}{l}\text { BSA } 2.2 \text { vs } 2.0 \text { among male } \\
\text { patients }\end{array}$ & 1.02 & $0.98-1.07$ & 1.03 & .3091 \\
\hline $\begin{array}{l}\text { BSA } 1.6 \text { vs } 2.0 \text { among female } \\
\text { patients }\end{array}$ & 1.30 & $1.12-1.51$ & 12.23 & $.0005^{*}$ \\
\hline $\begin{array}{l}\text { BSA } 1.8 \text { vs } 2.0 \text { among female } \\
\text { patients }\end{array}$ & 1.04 & $0.96-1.12$ & 0.72 & .3961 \\
\hline $\begin{array}{l}\text { BSA } 2.2 \text { vs } 2.0 \text { among female } \\
\text { patients }\end{array}$ & 1.17 & $1.02-1.34$ & 5.35 & .0207 \\
\hline Time trend: per 6-mo interval & 0.99 & $0.98-1.00$ & 6.49 & .0108 \\
\hline Noninsulin-dependent diabetes & 1.07 & $0.96-1.18$ & 1.57 & .2097 \\
\hline Insulin-dependent diabetes & 1.40 & $1.22-1.60$ & 23.35 & $<.0001^{*}$ \\
\hline Hypertension & 0.89 & $0.81-0.98$ & 6.01 & .0142 \\
\hline Severe chronic lung disease & 1.72 & $1.42-2.09$ & 30.19 & $<.0001^{*}$ \\
\hline Peripheral vascular disease & 1.18 & $1.07-1.3$ & 10.31 & .0013 \\
\hline CVD without CVA & 1.22 & $1.04-1.43$ & 5.69 & .0170 \\
\hline CVD with CVA & 1.17 & $1.01-1.37$ & 4.13 & .0421 \\
\hline Preoperative atrial fibrillation & 1.2 & $1.03-1.39$ & 5.6 & .0179 \\
\hline Immunosuppressive treatment & 1.39 & $109-1.77$ & 7.11 & .0077 \\
\hline Reoperation $\times 1$ & 2.35 & $1.63-3.38$ & 21.24 & $<.0001^{*}$ \\
\hline $\mathrm{PCI}<6 \mathrm{~h}$ & 1.50 & $1.35-1.68$ & 52.93 & $<.0001^{*}$ \\
\hline CHF/not NYHA IV & 1.03 & $0.89-1.20$ & 0.20 & .6586 \\
\hline CHF/NYHA IV & 1.18 & $1.07-1.30$ & 10.79 & $.001 *$ \\
\hline MI $<6 \mathrm{~h}$ vs MI $6-24 \mathrm{~h}$ & 1.05 & $0.97-1.14$ & 1.64 & .2010 \\
\hline Acuity status: emergency & 2.29 & $1.85-2.85$ & 56.90 & $<.0001 *$ \\
\hline $\begin{array}{l}\text { Acuity status: emergency/ } \\
\text { salvage }\end{array}$ & 6.43 & $5.13-8.06$ & 259.78 & $<.0001^{*}$ \\
\hline Cardiogenic shock & 2.79 & $2.51-3.09$ & 372.50 & $<.0001^{*}$ \\
\hline Preoperative IABP/inotropes & 1.14 & $1.04-1.25$ & 7.16 & .0074 \\
\hline $\begin{array}{l}\text { Diseased vessels ( } 2 \text { vs } 1 \text { or } \\
\quad 3 \text { vs } 2 \text { ) }\end{array}$ & 1.07 & $1.00-1.25$ & 4.01 & .0453 \\
\hline Left main disease & 1.07 & $0.99-1.15$ & 2.79 & .0948 \\
\hline Mitral insufficiency/severe & 1.42 & $0.98-2.07$ & 3.36 & .0667 \\
\hline $\begin{array}{l}\text { Tricuspid insufficiency: } \\
\text { moderate/severe }\end{array}$ & 1.60 & $1.21-2.10$ & 11.11 & .09 \\
\hline
\end{tabular}

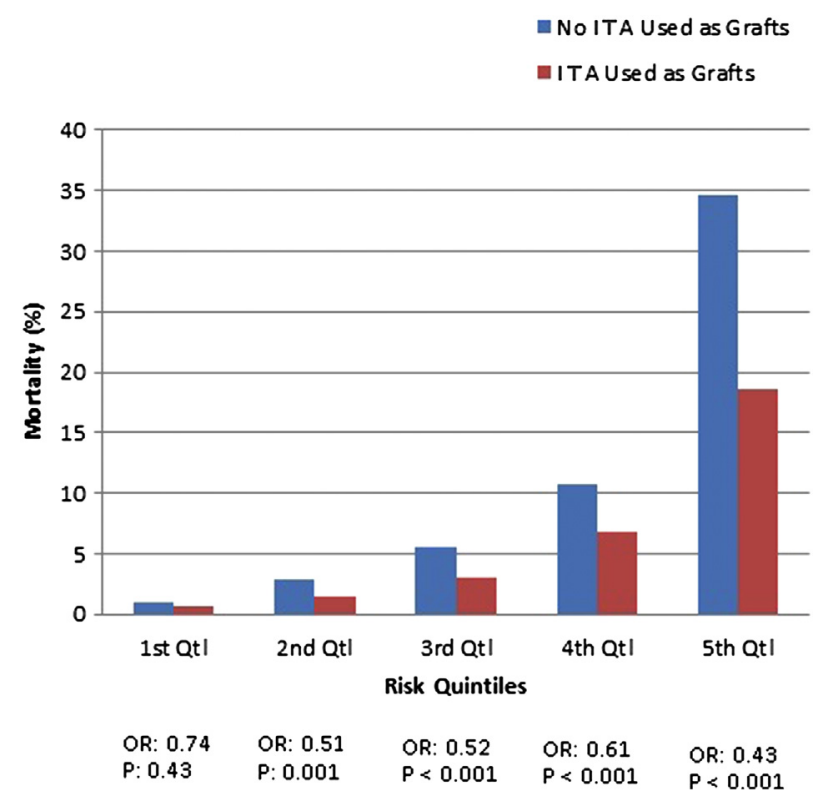

FIGURE 1. Influence of ITA grafting on operative mortality across increasing predicted risk categories after a recent MI ( $<24$ hours). ITA, Internal thoracic artery; $Q t l$, quintile; $O R$, odds ratio.

subgroups can be treated surgically if catheter-based methods fail or the coronary anatomy is inappropriate.

The positive benefits of ITA grafting on long-term survival, freedom from cardiac events, reoperation, and graft patency are well documented. ${ }^{19,20}$ Lower operative mortality also has been reported in the general population undergoing $\mathrm{CABG}^{21-23}$ However, outcomes with ITA grafting in the early post-MI state have not been studied, and in the present analysis, ITA grafting in patients with MI in less than 24 hours was associated with a halving of operative mortality. It is conceivable that unmeasured confounding variables or other methodologic factors were involved; however, this finding was consistent even in the highest risk quintile, and an adjusted OR for operative mortality of 0.52 is compelling. In fact, although patients postMI were not specifically defined, Edwards and colleagues ${ }^{23}$ presented a similar result using the STS database from 1987 to 1991 in patients undergoing general CABG. In that study, the mortality benefits of ITA grafting seemed to increase with baseline risk ${ }^{23}$ and to a similar degree as observed in the present series. Thus, it is possible that ITA use is actually beneficial in this setting, and increased ITA use could be associated with better surgical outcomes in the subgroup with MI in less than 24 hours. Possible mechanisms include better ITA graft function in the postischemic low-reflow state and better early and late graft patency; however, any of these hypotheses may err on the side of mere speculation because the early effects of ITA grafting in this patient population have not been addressed in the literature. This interesting finding deserves further clinical and physiologic investigation. 


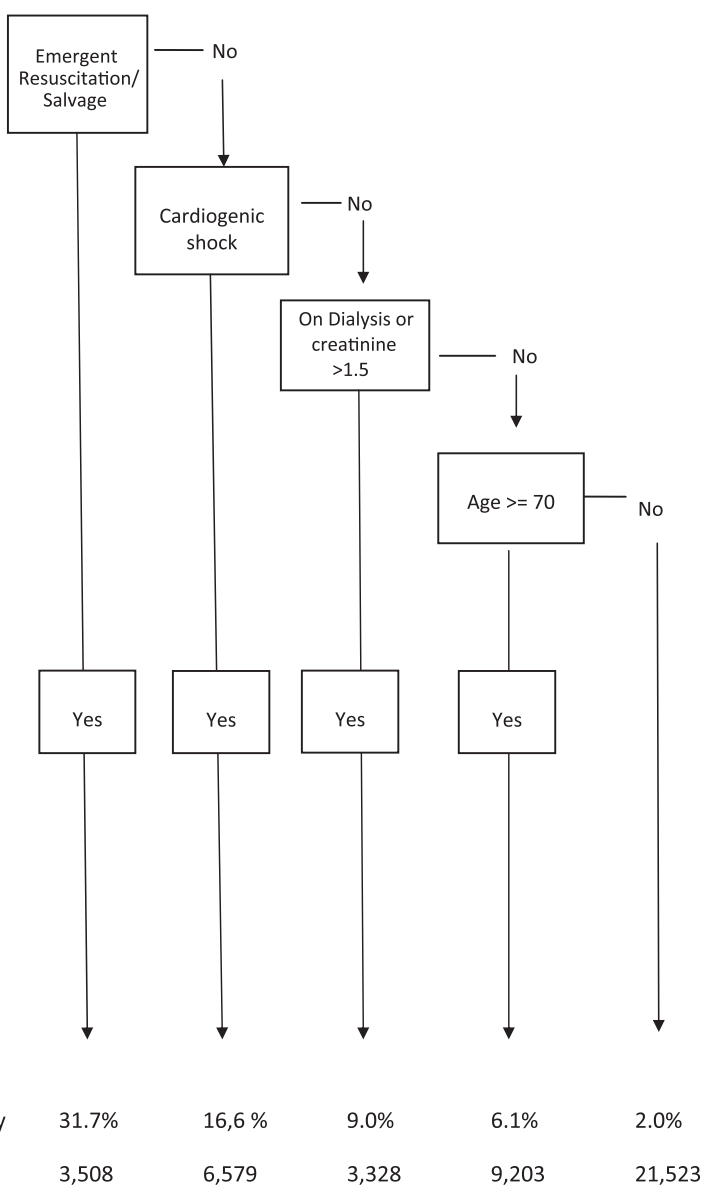

FIGURE 2. Classification tree for patients undergoing CABG surgery within 24 hours of an MI $(\mathrm{N}=44,141)$.

It is evident from the data presented that ITA use is lower in this patient population. Of note, the rate of ITA grafting is remarkably low in patients presenting in cardiogenic shock, who represent $21.2 \%$ (9355 patients) of the study sample. Although early improved outcomes with ITA grafting are debatable, the long-term benefit is not questionable. Although the low ITA use is likely related to the acuity of presentation, there is a lack of evidence in the literature to support improved early outcomes by avoiding ITA grafting in this patient group, approximately half of the patients in cardiogenic shock. Our interaction analysis shows that the outcomes in cardiogenic shock are not influenced by the use of ITA grafting. Considering these findings, it is likely that a large group of patients did not benefit long-term from this conduit under the overgeneralization that ITA grafting jeopardizes early outcomes. The implication is that ITA grafts might be harvested, even in the sickest patients, soon after initiating cardiopulmonary bypass and used in most post-MI situations. Although a $P$ value of .56 may be considered nearly significant for institutional studies, it is largely inadequate in large-scale multi-institutional registries, where minor differences can appear highly significant because of the large volume of patients included; thus, a $P$ value of .001 was used to test statistical significance in our study.

A limitation of any retrospective study relates to unmeasured variables that can influence outcomes, such as in our study. In the STS variable list, indications for early CABG $(<24$ hours) are not well documented, and MI may have resulted in many instances as a complication of PCI instead of an independent coronary event. Data regarding STsegment elevation acute MI versus non-ST-segment elevation acute MI categories were not available in the STS data set and might be important. The decision for surgical intervention could have been biased by the various treatment pathways and referral patterns among institutions. However, even considering these limitations, the STS database represents a unique data set for evaluating this subject, ${ }^{9,10}$ and the findings of this analysis represent a compelling concluding hypotheses deserving of future testing.

\section{CONCLUSIONS}

Well-documented high-risk variables are more prevalent during acute MI, and certain patient subgroups carry a substantial mortality risk after CABG. Selected patients with MI in less than 24 hours or in cardiogenic shock experience acceptable mortality and may benefit from early surgical revascularization. ITA grafting seems to be an effective strategy in this setting, may reduce operative mortality, and is probably underused in current practice.

\section{References}

1. Babaev A, Frederick PD, Pasta DJ, Every N, Sichrovsky T, Hochman JS, NRMI Investigators. Trends in management and outcomes of patients with acute myocardial infarction complicated by cardiogenic shock. JAMA. 2005; 294:448-54

2. Weiss ES, Chang DD, Joyce DL, Nwakanma LU, Yuh DD. Optimal timing of coronary artery bypass after acute myocardial infarction: a review of California discharge data. J Thorac Cardiovasc Surg. 2008;135:503-11.

3. Thielmann M, Neuhäuser M, Marr A, Herold U, Kamler M, Massoudy P, et al Predictors and outcomes of coronary artery bypass grafting in ST elevation myocardial infarction. Ann Thorac Surg. 2007;84:17-24.

4. Lee DC, Oz MC, Weinberg AD, Ting W. Appropriate timing of surgical intervention after transmural acute myocardial infarction. $J$ Thorac Cardiovasc Surg. 2003;125:115-9

5. Cucherat M, Bonnefoy E, Tremeau G. Primary angioplasty versus intravenous thrombolysis for acute myocardial infarction. Cochrane Database Syst Rev. 2003;3:CD001560.

6. Keeley EC, Boura JA, Grines CL. Primary angioplasty versus intravenous thrombolytic therapy for acute myocardial infarction: a quantitative review of 23 randomised trials. Lancet. 2003;361:13-20.

7. Kolh P, Wijns W, Danchin N, Di Mario C, Falk V, Folliguet T, et al. Task Force on Myocardial Revascularization of the European Society of Cardiology (ESC) and the European Association for Cardio-Thoracic Surgery (EACTS); European Association for Percutaneous Cardiovascular Interventions (EAPCI). Eur J Cardiothorac Surg. 2010;38(Suppl):S1-52.

8. Levine GN, Bates ER, Blankenship JC, Bailey SR, Bittl JA, Cercek B, et al 2011 ACCF/AHA/SCAI Guideline for Percutaneous Coronary Intervention: executive summary: a report of the American College of Cardiology Foundation/ American Heart Association Task Force on Practice Guidelines and the Society for Cardiovascular Angiography and Interventions. Circulation. 2011;124: 2574-609

9. Shahian DM, O'Brien SM, Filardo G, Ferraris VA, Haan CK, Rich JB, et al; Society of Thoracic Surgeons Quality Measurement Task Force. The Society 
of Thoracic Surgeons 2008 cardiac surgery risk models: part 1-coronary artery bypass grafting surgery. Ann Thorac Surg. 2009;88(1 Suppl):S2-22.

10. Caceres M, Braud RL, Garrett HE. A short history of the Society of Thoracic Surgeons national cardiac database: perceptions of a practicing surgeon. Ann Thorac Surg. 2010;89:332-9.

11. Silverman NA. The surgeon's role in the treatment of acute myocardial infarction. Surg Clin North Am. 1985;65:527-37.

12. Parikh SV, de Lemos JA, Jessen ME, Brilakis ES, Ohman EM, Chen AY, et al; CRUSADE and ACTION Registry-GWTG Participants. Timing of in-hospital coronary artery bypass graft surgery for non-ST-segment elevation myocardial infarction patients. Results from the National Cardiovascular Data Registry ACTION Registry-GWTG (Acute Coronary Treatment and Intervention Outcomes Network Registry-Get With The Guidelines). JACC Cardiovasc Interv. 2010;3:419-27.

13. Hochman JS, Sleeper LA, Webb JG, Sanborn TA, White HD, Talley JD, et al. Early revascularization in acute myocardial infarction complicated by cardiogenic shock. SHOCK Investigators. Should We Emergently Revascularize Occluded Coronaries for Cardiogenic Shock. N Engl J Med. 1999;26:625-34.

14. Mehta RH, Grab JD, O'Brien SM, Glower DD, Haan CK, Gammie JS, et al; Society of Thoracic Surgeons National Cardiac Database Investigators. Clinical characteristics and in-hospital outcomes of patients with cardiogenic shock undergoing coronary artery bypass surgery: insights from the Society of Thoracic Surgeons National Cardiac Database. Circulation. 2008;117:876-85.

15. Haan CK, O'Brien S, Edwards FH, Peterson ED, Ferguson TB. Trends in emergency coronary artery bypass grafting after percutaneous coronary intervention, 1994-2003. Ann Thorac Surg. 2006;81:1658-65.
16. Bridges CR, Edwards FH, Peterson ED, Coombs LP, Ferguson TB. Cardiac surgery in nonagenarians and centenarians. J Am Coll Surg. 2003;197: 347-56.

17. Haan CK, Cabral CI, Conetta DA, Coombs LP, Edwards FH. Selecting patients with mitral regurgitation and left ventricular dysfunction for isolated mitral valve surgery. Ann Thorac Surg. 2004;78:820-5.

18. Mehta RH, Eagle KA, Coombs LP, Peterson ED, Edwards FH, Pagani FD, et al; Society of Thoracic Surgeons National Cardiac Registry. Influence of age on outcomes in patients undergoing mitral valve replacement. Ann Thorac Surg. 2002; 74:1459-67.

19. Loop FD, Lytle BW, Cosgrove DM, Stewart RW, Goormastic M, Williams GW, et al. Influence of the internal-mammary-artery graft on 10-year survival and other cardiac events. $N$ Engl J Med. 1986;314:1-6.

20. Rankin JS, Tuttle RH, Wechsler AS, Teichmann TL, Glower DD. Techniques and benefits of multiple internal mammary artery bypass at 20-years of followup. Ann Thorac Surg. 2007;83:1549-55.

21. Gardner TJ, Greene PS, Rykiel MF, Baumgartner WA, Cameron DE, Casale AS, et al. Routine use of the left internal mammary artery graft in the elderly. Ann Thorac Surg. 1990;49:188-93.

22. Grover FL, Johnson RR, Marshall G, Hammermeister KE. Impact of mammary grafts on coronary bypass operative mortality and morbidity. Department of Veterans Affairs Cardiac Surgeons. Ann Thorac Surg. 1994;57:559-68.

23. Edwards FH, Clark RE, Schwartz M. Impact of internal mammary artery conduits on operative mortality in coronary revascularization. Ann Thorac Surg. 1994;57:27-32 